\title{
Early physical therapy for a patient affected by coronavirus disease 2019 (COVID-19) on awake veno-venous extracorporeal membrane oxygenation: a case report
}

\author{
Haijun $\mathrm{Li}^{1} \wedge$, Jinxiu Chen ${ }^{1}$, Ying Yu ${ }^{1}$, Lin Mao ${ }^{1}$, Lunjie Luo ${ }^{1}$, Liliang Zou ${ }^{1}$, Tianfang Zhang ${ }^{1}$, Jian Yang ${ }^{2}$, \\ Zuobing Chen ${ }^{1}$ \\ ${ }^{1}$ Department of Rehabilitation Medicine, The First Affiliated Hospital, Zhejiang University School of Medicine, Hangzhou, China; ${ }^{2}$ Department of \\ Cardiology, The First Affiliated Hospital, Zhejiang University School of Medicine, Hangzhou, China \\ Correspondence to: Jian Yang. Department of Cardiology, The First Affiliated Hospital, Zhejiang University School of Medicine, Hangzhou 310000, \\ China. Email: 1313027@zju.edu.cn; Zuobing Chen. Department of Rehabilitation Medicine, The First Affiliated Hospital, Zhejiang University \\ School of Medicine, Hangzhou 310000, China. Email: czb1971@zju.edu.cn.
}

\begin{abstract}
Since December 8, 2019, an acute respiratory illness has spread rapidly in China, causing 3,097 people to die as of March 7, and it has become a global crisis. The common symptoms are fever, fatigue, dry cough, myalgia, and dyspnea. This case report presents a 36-year-old male who was diagnosed with severe acute respiratory syndrome coronavirus 2 (SARS-CoV-2) infected pneumonia on February 2, 2020. This patient received veno-venous extracorporeal membrane oxygenation (V-V ECMO) last for 10 days as salvage treatment as his condition became critical in the acute setting. As soon as his status became stable, he began to receive an early rehabilitation program performed by our rehabilitation team. After 43 days of treatment under the efforts of our teamwork, the patient was able to walk 800 meters, and then was discharged the next day. To our knowledge, this is the first report of early physical therapy for a patient with coronavirus disease 2019 (COVID-19) who was receiving extracorporeal membrane oxygenation (ECMO) whilst awake. This case indicates that early physical rehabilitation is safe and feasible and resulted in an expedited recovery using ECMO whilst awake. The goals for physiotherapy management include avoiding atelectasis, airway clearance, weaning and increasing the functional level. This report may contribute to the current literature on early physical therapy rehabilitation programs for awake ECMO patients.
\end{abstract}

Keywords: Coronavirus disease 2019 (COVID-19); SARS-CoV-2; awake extracorporeal membrane oxygenation; early physical therapy; case report

Submitted Dec 14, 2021. Accepted for publication Jan 20, 2022.

doi: 10.21037/atm-22-177

View this article at: https://dx.doi.org/10.21037/atm-22-177

\section{Introduction}

Since early December of 2019, a novel viral pneumonia has spread rapidly across the world creating a global public health crisis. As of March 15, the World Health Organization (WHO) had recorded 152,428 confirmed cases, and 5,720 deaths among 141 countries and regions. Some studies suggest COVID-19 infects older adults more easily, especially those with chronic disease. The common symptoms are fever, fatigue, dry cough, myalgia, and dyspnea $(1,2)$. Although the case fatality rate of COVID-19 is lower, the total number of deaths has been much greater than that of Middle East Respiratory Syndrome Coronavirus (MERS-CoV) and severe acute respiratory syndrome coronavirus (SARS-CoV) (3).

^ ORCID: 0000-0001-6852-2719. 


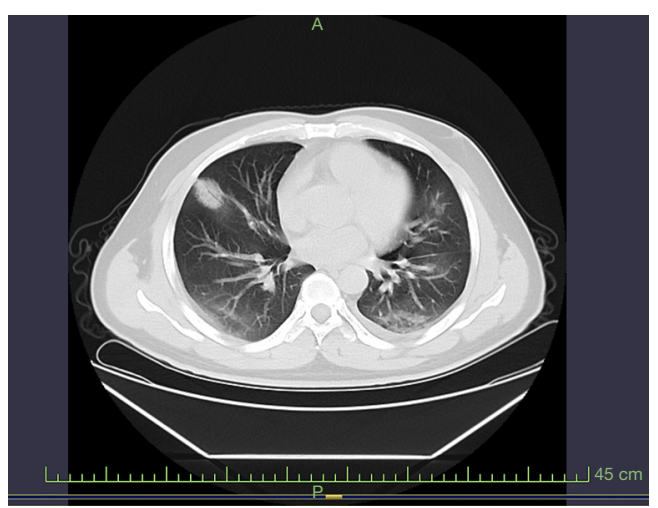

Figure 1 Computed tomography scans of a 36-year-old man with coronavirus Disease 2019 (COVID-19) on February 3.

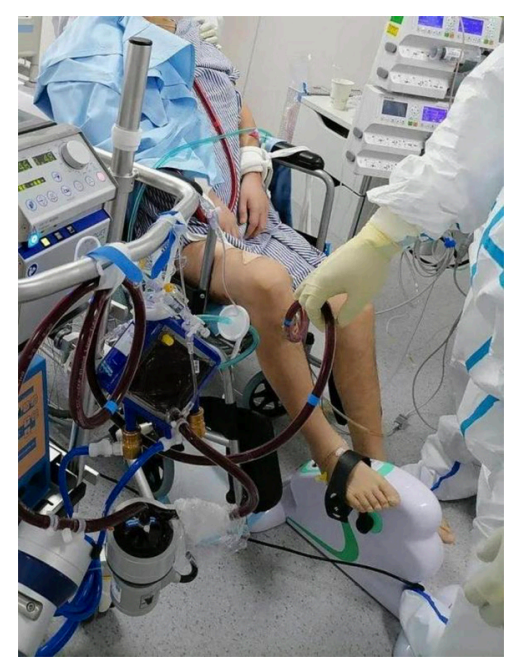

Figure 2 Patient cycling bedside with the multidisciplinary team.

Extracorporeal Membrane Oxygenation is regarded as a salvage therapy for critical patients in the acute setting. Decreases in cardiorespiratory and musculoskeletal function commonly occur in patients on ECMO support because of immobilization and prolonged bedrest (4). Early physical therapy is crucial, and has been demonstrated to be safe and feasible in our patients. The goals for physiotherapy management include avoiding atelectasis, airway clearance, weaning and increasing the functional level. In this report, we discuss a successful early physical therapy intervention in a COVID-19 patient on ECMO. We present the following article in accordance with the CARE reporting checklist (available at https://atm.amegroups.com/article/ view/10.21037/atm-22-177/rc).

\section{Case presentation}

A 36-year-old male travelled to Malaysia on January $19^{\text {th }}$ 2020 after visiting Wuhan on the same day. On January $24^{\text {th }}$, he returned to Hangzhou City and was immediately isolated. Three days later, he presented to the Xiaoshan Hospital with low grade fever accompanied by cough, sputum and headache. Whilst initially testing negative to the novel coronavirus nucleic acid screening test on several occasions, on February $2^{\text {nd }}$, the patient's nucleic acid test for the SARS-CoV-2 was positive, and his body temperature rose to $39{ }^{\circ} \mathrm{C}$. A bilateral lung infection was discovered on chest imaging examination (Figure 1) which matched COVID-19 imaging manifestations. At that time, the patient was transferred to the negative pressure ward as his symptoms worsened. After hospitalization, he received antiviral treatment including antiviral drugs and interferon atomization inhalation. On February $6^{\text {th }}$, dyspnea still existed, and the patient's oxygenation index was low, despite his oxygen concentration increasing to $67 \%$. On this basis, he was transferred to the intensive care unit (ICU) and intubated: $\mathrm{FiO}_{2} 80 \%, \mathrm{SPaO}_{2} 96, \mathrm{~T} 37.9^{\circ} \mathrm{C}$, BP 129/78 mmHg, HR 79 beats/min, RR 32 breaths/min, $\mathrm{pH}$ 7.5, $\mathrm{PaCO}_{2} 32 \mathrm{mmHg}, \mathrm{PaO}_{2} 57.6 \mathrm{mmHg}$ (temperature corrected). After receiving closed thoracic drainage and artificial liver catheterization three times, his lung tissue was seriously damaged, and he received ECMO support in ICU Day 8. On day 12 in the ICU, his endotracheal intubation was removed. The following day, he commenced early physical therapy with our rehabilitation team while undergoing ECMO whilst awake.

Initially the patient was placed in a seated position on the edge of his hospital bed for at least 30 minutes while undergoing physical therapy. As the patient improved, he began using a modified cycle placed beside the bed (Figure 2). On February $20^{\text {th }}$, he was moved from the isolation ward, as two of his consecutive respiratory specimens were negative on the nucleic acid tests (interval $\geq 24$ hours). After sixth days of physical therapy intervention, the patient could hold a standing position for 10 seconds dependently. He was successfully removed from ECMO support after 20 days of treatment in the ICU: $\mathrm{FiO}_{2} 21 \%, \mathrm{SPaO}_{2} 96, \mathrm{~T} 37.1{ }^{\circ} \mathrm{C}$, BP 143/59 mmHg, HR 118 beats/min, RR 17 breaths/min, $\mathrm{pH}$ 7.37, $\mathrm{PaCO}_{2} 36.5 \mathrm{mmHg}$ (temperature corrected), $\mathrm{PaO}_{2}$ $100 \mathrm{mmHg}$ (temperature corrected).

In this case, the Physical Function ICU Test (PFIT) was used as an outcome measure. The PFIT is designed for the purpose of prescribing and evaluating progress in patients 
who are critically ill, and has been found to be valid and sensitive to detect change in the ICU population (5). The patient obtained a PFTT score of 3 on the first day he received the rehabilitation program and score of 10 (stepped 98 steps/min) after 17 days of physical therapy intervention. After 43 days of treatment the patient was discharged with no obvious severe disability. After receiving a 26-day physical therapy program, he performed well, and was able to walk 800 meters independently the day before discharge. There were significant changes in the physical performance component, from disability to sit to stand to independent standing.

All procedures performed in this study were in accordance with the ethical standards of the institutional and/or national research committee(s) and with the Helsinki Declaration (as revised in 2013). Written informed consent was obtained from the patient for publication of this case report and accompanying images. A copy of the written consent is available for review by the editorial office of this journal.

\section{Discussion}

This case details a patient who experienced advanced recovery from awake ECMO by receiving an early rehabilitation program, which included a combination of body positioning, breathing control maneuvers, range of motion (ROM) exercises, and mobilization.

According to the Diagnosis and Treatment of Pneumonia for Novel Coronavirus Infection (Trial Version 7) (6), ECMO is regarded as a rescue therapy for critically ill patients affected by COVID-19, which has a role in the management of these critically ill patients, since there is currently no specialized pharmaceutical treatment for this disease. The elementary pathophysiology of severe novel coronavirus infection is severe acute respiratory distress syndrome (ARDS). In patients with ARDS, severe physical deconditioning and lower levels of functional and life quality can be seen (7-9). To maintain muscle strength and physical function, we used awake ECMO, which allows patients to communicate, feed, and participate actively in early physical rehabilitation programs.

Previous studies have shown that early rehabilitation programs for patients undergoing ECMO should be implemented by a multidisciplinary team that includes a surgeon, nurse, perfusionist, intensive care physicians, respiratory therapist, and physical therapist $(10,11)$. This protocol was adopted in this case. Mobilization with ECMO is a high-risk intervention that is appropriate for only a small number of candidates eligible for standing or ambulation, even though it has been proven to be both safe and practicable in patients with respiratory failure $(12,13)$. However, positioning and mobilization should be performed carefully because of the presence of cannulas. Generally, passive movement is the preferred first physiotherapeutic intervention in order to prevent further muscular contracture, to maintain joint mobility and soft tissue extensibility, and improve functional performance (14). The early physical therapy interventions in our program included mobilization (passive or active motions and postural changes), positioning, (either sitting or upright in bed) and ambulation (with or without aid), which are the most commonly used interventions in subjects receiving awake ECMO. These were initiated in a step by step manner.

This case confirms the benefits of early physiotherapy on awake patients receiving ECMO seen in other studies. This intervention may accelerate the recovery process, by improving physical and mental status, in addition to overall outcomes (4). With a significant increase in the number of severely ill patients infected by COVID-19, more temporary ICUs are being established and a shorter length of ICU stay is required. Early physical therapy is recommended in these cases (15).

\section{Conclusions}

This case demonstrates that early physical therapy is both safe and feasible and may contribute to an expedited recovery in patients receiving awake ECMO. To our knowledge, there are only a small number of studies reporting the effect of early physical therapy on patients with COVID-19 who are receiving awake ECMO. These results may contribute to the current literature on early physical therapy rehabilitation programs for awake ECMO patients.

\section{Acknowledgments}

Funding: This work was supported by the Natural Science Foundation of Zhejiang Province (No. LGF18H170002) and a university level project of Zhejiang University (Research on governance performance and advantages of health system with Chinese characteristics from the perspective of Sino US comparison, No. 2-2050205-21-688). 


\section{Footnote}

Reporting Checklist: The authors have completed the CARE reporting checklist. Available at https://atm.amegroups. com/article/view/10.21037/atm-22-177/rc

Conflicts of Interest: All authors have completed the ICMJE uniform disclosure form (available at https://atm. amegroups.com/article/view/10.21037/atm-22-177/coif). The authors have no conflicts of interest to declare.

Ethical Statement: The authors are accountable for all aspects of the work in ensuring that questions related to the accuracy or integrity of any part of the work are appropriately investigated and resolved. All procedures performed in this study were in accordance with the ethical standards of the institutional and/or national research committee(s) and with the Helsinki Declaration (as revised in 2013). Written informed consent was obtained from the patient for publication of this case report and accompanying images. A copy of the written consent is available for review by the editorial office of this journal.

Open Access Statement: This is an Open Access article distributed in accordance with the Creative Commons Attribution-NonCommercial-NoDerivs 4.0 International License (CC BY-NC-ND 4.0), which permits the noncommercial replication and distribution of the article with the strict proviso that no changes or edits are made and the original work is properly cited (including links to both the formal publication through the relevant DOI and the license). See: https://creativecommons.org/ licenses/by-nc-nd/4.0/.

\section{References}

1. Chen N, Zhou M, Dong X, et al. Epidemiological and clinical characteristics of 99 cases of 2019 novel coronavirus pneumonia in Wuhan, China: a descriptive study. Lancet 2020;395:507-13.

2. Wang D, Hu B, Hu C, et al. Clinical Characteristics of 138 Hospitalized Patients With 2019 Novel CoronavirusInfected Pneumonia in Wuhan, China. JAMA 2020;323:1061-9.

3. Yang X, Yu Y, Xu J, et al. Clinical course and outcomes of critically ill patients with SARS-CoV-2 pneumonia in Wuhan, China: a single-centered, retrospective, observational study. Lancet Respir Med
2020;8:475-81.

4. Wells CL, Forrester J, Vogel J, et al. Safety and Feasibility of Early Physical Therapy for Patients on Extracorporeal Membrane Oxygenator: University of Maryland Medical Center Experience. Crit Care Med 2018;46:53-9.

5. Tadyanemhandu C, Manie S. Implementation of the physical function ICU test tool in a resource constrained intensive care unit to promote early mobilisation of critically ill patients- a feasibility study. Arch Physiother 2016;6:12.

6. National Health Commission \& National Administration of Traditional Chinese Medicine. Diagnosis and Treatment Protocol for NovelCoronavirus Pneumonia (Trial Version 7). Chin Med J 2020;133:E027. doi: 10.3760/cma. j.issn.0366-6999.2020.0027. Available online: http:// rs.yiigle.com/yufabiao/1184760.htm

7. Peck TJ, Hibbert KA. Recent advances in the understanding and management of ARDS. F1000Res 2019;8:F1000 Faculty Rev-1959.

8. Fan E, Brodie D, Slutsky AS. Acute respiratory distress syndrome: advances in diagnosis and treatment. JAMA 2018;319:698-710.

9. Thompson BT, Chambers RC, Liu KD. Acute respiratory distress syndrome. $\mathrm{N}$ Engl J Med 2017;377:562-72.

10. Abrams D, Javidfar J, Farrand E, et al. Early mobilization of patients receiving extracorporeal membrane oxygenation: a retrospective cohort study. Crit Care 2014;18:R38.

11. Ferreira DDC, Marcolino MAZ, Macagnan FE, et al. Safety and potential benefits of physical therapy in adult patients on extracorporeal membrane oxygenation support: a systematic review. Rev Bras Ter Intensiva. 2019;31:227-39.

12. Zhu Y, Bankar D, Shudo Y, et al. Multidisciplinary approach utilizing early, intensive physical rehabilitation to accelerate recovery from veno-venous extracorporeal membrane oxygenation. Eur J Cardiothorac Surg 2019;56:811-2.

13. Hodgson CL, Bailey M, Bellomo R, et al. A Binational Multicenter Pilot Feasibility Randomized Controlled Trial of Early Goal-Directed Mobilization in the ICU. Crit Care Med 2016;44:1145-52.

14. Munshi L, Kobayashi T, DeBacker J, et al. Intensive Care Physiotherapy during Extracorporeal Membrane 
Oxygenation for Acute Respiratory Distress Syndrome. Ann Am Thorac Soc 2017;14:246-53.

15. Ko Y, Cho YH, Park YH, et al. Feasibility and Safety

Cite this article as: $\mathrm{Li} \mathrm{H}$, Chen J, Yu Y, Mao L, Luo L, Zou L, Zhang T, Yang J, Chen Z. Early physical therapy for a patient affected by coronavirus disease 2019 (COVID-19) on awake veno-venous extracorporeal membrane oxygenation: a case report. Ann Transl Med 2022;10(5):264. doi: 10.21037/atm-22177 of Early Physical Therapy and Active Mobilization for Patients on Extracorporeal Membrane Oxygenation. ASAIO J 2015;61:564-8. 